\title{
DUALITY OF THE ELECTORAL AND LEGAL CULTURE AND POLITICAL COMMUNICATION IN THE ELECTIONS OF THE LANDTAG OF PRUSSIA (1849-1918) ${ }^{1}$
}

\author{
Yuri A. Bokov \\ Volgograd State University, Volgograd, Russian Federation \\ Erwin A. Akhverdiev \\ Central Office of the Federal Tax Service of Russia, Moscow, Russian Federation
}

Introduction: based on a wide range of historical sources about the elections of the Landtag of Prussia in 1849-1918, an attempt is made to examine the electoral and legal culture through the prism of political communication. The aim of the research is a comprehensive analysis of the relationship between the communication processes and the level of electoral and legal culture of Prussian residents in 1849-1918. Results: the paper substantiates the conclusion that the study of political culture should not be limited to the analysis of the level of participation, but it is necessary to equally study political behavior in a very broad sense, since both are inextricably linked. On the example of the election campaigns to the Landtag of Prussia in 1849-1918 it is noted that the rejection of the current situation in the state leads to a decrease in the level of public participation in the elections, while low turnout is not always a consequence of an insufficient level of electoral and legal culture. Conclusions: the political and legal culture of the inhabitants of Prussia, their legendary habit of observing the law, had a decisive influence on the choice of the type of political communication. The Prussians, preferring legal forms of political communication, thereby confirmed their faith in the law, in the institution of elections. Political communication should not be limited to periodic voting. Citizens should be given the rights to influence the functioning of the state. If these requirements are not met, the legal types of political communication, even with a sufficiently high level of legal culture of the population, are replaced by semi-legal and illegal ones, and the reformist mode of activity of political forces is changed to a revolutionary one.

Key words: elections, electoral and legal culture, political communication, the Landtag of Prussia, class electoral system, electoral law.

Citation. Bokov Yu.A., Akhverdiev E.A. Duality of the Electoral and Legal Culture and Political Communication in the Elections of the Landtag of Prussia (1849-1918). Legal Concept = Pravovaya paradigma, 2020, vol. 19, no. 4, pp. 63-68. (in Russian). DOI: https://doi.org/10.15688/lc.jvolsu.2020.4.8

\section{ДВУЕДИНСТВО ЭЛЕКТОРАЛЬНО-ПРАВОВОЙ КУЛЬТУРЫ И ПОЛИТИЧЕСКОЙ КОММУНИКАЦИИ НА ВЫБОРАХ ПРУССКОГО ЛАНДТАГА (1849-1918 гГ.) ${ }^{1}$}

\section{Юрий Александрович Боков}

Волгоградский государственный университет, г. Волгоград, Российская Федерация

\section{Эрвин Алибекович Ахвердиев}

Центральный аппарат Федеральной налоговой службы России, г. Москва, Российская Федерация 
Введение: на основе обширного спектра исторических источников о выборах ландтага Пруссии в 1849-1918 гг. предпринята попытка рассмотреть электорально-правовую культуру через призму политической коммуникации. В качестве цели исследования определен комплексный анализ взаимосвязи коммуникативных процессов и уровня электорально-правовой культуры жителей Пруссии в 1849-1918 годах. Результаты: в работе обосновывается вывод, что исследование политической культуры не следует ограничивать анализом уровня участия, а необходимо одинаково изучать политическое поведение в очень широком смысле, поскольку и то и другое неразрывно связаны. На примере избирательных кампаний в Прусский ландтаг в 1849-1918 гг. отмечается, что неприятие существующего положения в государстве приводит к снижению уровня участия населения на выборах, при этом низкая явка не всегда является следствием недостаточного уровня электорально-правовой культуры. Выводы: политико-правовая культура жителей Пруссии, их легендарная привычка соблюдать закон оказывали определяющее влияние на выбор вида политической коммуникации. Пруссаки, отдавая предпочтение легальным видам политической коммуникации, тем самым подтверждали свою веру в закон, в институт выборов. Политическая коммуникация не должна ограничиваться лишь периодически проводимым голосованием. Гражданам должны быть предоставлены права, позволяющие влиять на функционирование государства. В случае несоблюдения данных требований, легальные виды политической коммуникации, даже при достаточно высоком уровне правовой культуры населения, сменяются полулегальными и нелегальными, а реформистский способ деятельности политических сил меняется на революционный.

Ключевые слова: выборы, электорально-правовая культура, политическая коммуникация, ландтаг Пруссии, классовая избирательная система, избирательное право.

Цитирование. Боков Ю. А., Ахвердиев Э. А. Двуединство электорально-правовой культуры и политической коммуникации на выборах Прусского Ландтага (1849-1918 гг.) // Legal Concept = Правовая парадигма. - 2020. - Т. 19, № 4. - C. 63-68. - DOI: https://doi.org/10.15688/lc.jvolsu.2020.4.8

В первых эмпирических работах по политической коммуникации поведенческий репертуар населения определялся как пирамида действий, в основе которой находятся: активность зрителей-участников, их информированность и выборы. Вершину пирамиды политического участия составляли «гладиаторские поединки» - активное участие в партиях и органах принятия политических решений [7]. Таким образом, в основе политической коммуникации выделялось четыре измерительные величины: выборы, участие в избирательной кампании, активность населения (включающая в себя протестные акции).

В настоящее время вызывает некоторое удивление феномен политической активности граждан в XIX - начале XX в. в отстаивании и реализации политических, в особенности избирательных, прав и свобод. Граждане массово участвовали в политических демонстрациях, работе политических партий, выборах. Проанализируем взаимосвязь коммуникационных процессов и электоральной культуры на выборах ландтага королевства Пруссии в период с 1849 по 1918 год.

Королевским указом прусского короля Фридриха Вильгельма IV от 30 мая 1849 г. для избрания ландтага - нижней палаты прус- ского парламента (Verordnung über die Ausführung der Wahl der Abgeordneten zur Zweiten Kammer) [10, S. 205] было установлено трехклассное избирательное право («Dreiklassenwahlrecht»), просуществовавшее c незначительными изменениями до 1918 года. Целью установления классового избирательного права было наделение элит более значительным количеством голосов и сокращение числа небогатых избирателей [4, S. 116]. Замена существовавшего относительно демократичного для своего времени избирательного права (относительно всеобщего мужского избирательного права) [1, с. $104-$ 105] реакционным избирательным правом воспринималась значительной частью населения негативно. Однако существенных действий, направленных на защиту ранее действовавшего избирательного права, не предпринималось. На наш взгляд, на выбор форм защиты ущемленного права, форм политической коммуникации оказывал влияние уровень политико-правовой культуры жителей Пруссии, их известная привычка соблюдать закон.

На основании указа короля избиратели разделялись на три класса в зависимости от уплачиваемых прямых государственных налогов (подоходный налог, налог на имущество 
и строительный налог, налог на торговлю плюс налог на компанию). Только с 1 апреля 1895 г. прямые коммунальные, районные и провинциальные налоги стали также учитываться. Для каждого лица, не облагаемого государственным подоходным налогом, для расчета применялась условная сумма (якобы уплачиваемых платежей), равная трем маркам. Лица, освобожденные от уплаты налогов, относились к тому отделению, к которому принадлежали бы в том случае, если бы платили их.

Министр внутренних дел Пруссии Ф. Эйленбург, пытаясь найти хоть какие-то достоинства действующей избирательной системы, указывал на следующее: «Никто, даже в низшем классе, не может голосовать иначе, чем если бы он был в состоянии уплачивать более высокий доход. Трехклассная избирательная система оценена чрезмерно строго и в большинстве случаев не объективно. В основу системы положена важнейшая идея, согласно которой в отношении выборов тот должен иметь больше полномочий, кто платит больше налогов. Насколько я знаю, это еще не оспаривалось, разве что теми, которые вообще при любых обстоятельствах утверждают, что всеобщее избирательное право - единственное средство спасения всех нас. Но тот, кто не придерживается этой точки зрения, должен быть в состоянии признать, что в системе трехклассного голосования есть обоснованная мысль» $[9$, S. 3].

Противники трехклассной избирательной системы характеризовали ее как право выбора не человека, а денежного мешка. На избирательной листовке под названием «Три класса избирателей» («Die drei Wählerklassen»), изданной социал-демократической партией к выборам 1908 г., была представлена карикатура на несправедливость распределения избирателей по классам в Пруссии. На листовке изображен мешок с деньгами крупного налогоплательщика, относящегося к первому классу, и указана на этом мешке цифра «10 000», обозначающая количество принадлежащих ему денег и соответственно голосов на выборах. Далее изображен представитель второго класса с мешком поменьше с цифрой «1 000». Представитель третьего класса с мешочком, на котором виднеется цифра «1» [3, с. б/нумерации].
Широкие массы населения требовали демократизации избирательного права, указывая, что они вносят более весомый вклад в развитие страны, чем считают сторонники трехклассной избирательной системы. 7 марта 1910 г. в Берлине была проведена крупнейшая в истории демонстрация с требованиями изменения избирательного законодательства, позволявшего поддерживать правление юнкеров. В демонстрации участвовало приблизительно от 50000 - по данным полиции [6, S. 1] и до 150000 человек - по данным социал-демократической партии $[11, \mathrm{~S} .1)$.

Система выборов в Прусский ландтаг составляла предмет серьезного раздора между либеральными и консервативными партиями Германии. Либерализации избирательного права требовали даже наиболее умеренные среди левых парламентских партий, например, национал-либералы. Во всей Пруссии буржуазия и рабочие протестуют против сохранения классовой системы выборов [2, л. 199].

Массовые акции прусских социал-демократов против трехклассной избирательной системы, низкая явка избирателей, которая составляла в среднем менее одной трети, свидетельствуют о неудовлетворенности населения существующим положением.

В политической коммуникации важную роль играют средства массовой информации, деятельность которых направлена на формирование общественного мнения. Эта роль средств массовой информации лучше всего прослеживается в избирательных кампаниях, потому что политические игроки представляют там свою работу и замысел в относительно концентрированной форме. Избирательные кампании относительно наглядны и потому легче поддаются анализу, чем политическая деятельность в целом.

В Пруссии накануне выборов традиционно появлялось значительное количество статей, посвященных предвыборной агитации и направленных на формирование общественного мнения. Существенное значение играли проправительственные издания, тиражи которых были сравнительно высокими.

Полуофициальной газетой прусского правительства была «Neueste Mittheilungen». Обратим внимание на некоторые опубликованные в ней агитационные материалы. «День 
выборов на пороге! Пусть каждый избиратель осознает высокую ответственность и долг, которые, учитывая наше великое прошлое, сейчас находятся на наших плечах. С гордостью мы можем оглянуться на то, что создал великий император и что благодаря ему стало нашим достоянием. Захочет ли какое-нибудь легкомысленное сердце поставить под сомнение или под угрозу наше здоровое государственное развитие? Опыт истории учит нас, что последствия политики часто бывают другими, чем предполагают ее идеологи, и что однажды ошибочные пути могут легко привести к тревожным потрясениям. Напомним лишь о периоде начала правления великого императора, когда либеральные идеи имели преобладающий характер и в соблазнительной форме превозносились как единственное средство социального и государственного блага. Потребовалось много усилий и труда, чтобы возместить причиненный ими ущерб. И теперь эти идеи, хотя и в несколько ином виде, звучат снова, выражается мнение, что в настоящее время пришло время для их реализации. Кто может это знать? Но одно несомненно, то что этим будут проложены пути, которые постепенно отводят далеко от твердынь, лежащих в основе трудов великого императора и должны привести к серьезной, тяжелой борьбе за трон и Отечество. Наша история настойчиво призывает нас к напоминанию: “храни то, что у тебя есть!” Имея это в виду, избиратели, придерживайтесь старого лозунга: “С Богом за царя и Отечество!”» $[8$, S. 1].

Представленные примеры публикаций наглядно демонстрируют желание их авторов повлиять на электоральное поведение граждан путем воззвания к их ценностям и убеждениям. Обращение к читателям преследует цель не только поддержки проправительственных партий, но и увеличение явки на избирательные участки. Участие в голосовании преподносилось как активный гражданский долг добропорядочного жителя. Авторами публикаций презюмировалось, что среди не явившихся сторонников короля больше, чем противников. Кроме того, при агитации за явку, в расчет бралось и то, что не у каждого пришедшего на избирательный участок (при отсутствии принципа тайны голосования) хватит духу открыто про- голосовать за партии, выступающие против существующего режима, против короля.

Исследование политической культуры не должно ограничиваться только анализом уровня участия, но и должно одинаково изучать политическое поведение в очень широком смысле, поскольку и то и другое неразрывно связано. Анализ статистических данных показывает, что значительная часть граждан бойкотировали выборы ландтага Пруссии в знак протеста против существующего избирательного права. Многие левые партии, в особенности социал-демократы, агитировали своих сторонников не участвовать в голосовании. Социал-демократы активно голосовали за кандидатов в депутаты Германского рейхстага, однако до 1900 г. не принимали участие в избрании Прусского ландтага (не только не выдвигали своих кандидатов, но даже не принимали участия в избрании выборщиков).

На выборах Германского рейхстага жители Пруссии принимали более активное участие, чем на выборах Прусского ландтага. Данное обстоятельство, очевидно, свидетельствует о том, что некоторые граждане не принимали существующую трехклассную избирательную систему и своим бойкотом пытались повлиять на ее демократизацию. В данном случае низкая явка на выборах не являлась безусловным следствием низкого уровня электорально-правовой культуры населения Пруссии, а, наоборот, может свидетельствовать о ее высоком уровне. Воздерживаясь от участия в голосовании, граждане тем самым пытались использовать преимущественно законные механизмы противодействия антидемократическим изменениям в избирательном праве.

Если провести классификацию политической коммуникации на виды, то можно выделить легальные и нелегальные. Пруссаки использовали преимущественно легальные виды коммуникации: выборы, собрания, демонстрации и др. Хотя применялись и нелегальные виды, например, выпуск и распространение запрещенных изданий. Отдавая предпочтениелегальным видам коммуникации, жители Пруссии тем самым подтверждали свою веру в закон, в институт выборов.

Н. Гаш указывает, что политическая система заинтересована в создании, поддер- 
жании и распространения позиции, согласно которой существующие политические институты являются наилучшими возможными для данного общества. Для эффективного функционирования существующей политической системы, среди прочих инструментов могут применяться «электоральное насилие», «коррумпированность», «компромиссные выборы» [5, p. 107].

Участие населения в функционировании государственной власти посредством процедуры выборов относится к основным формам осуществления демократии. Выборы и избирательные кампании в свете некоторых современных исследований политической культуры рассматриваются как условия для развития политической коммуникации. При этом политическая коммуникация не должна ограничиваться лишь периодически проводимым голосованием. Граждане должны быть наделены правами, позволяющими влиять на функционирование государства.

Под политическим участием понимаются действия граждан с целью оказания влияния на политические, кадровые решения или участия в их принятии. Важное значение имеет активность и гражданственность населения, уровень правовой, электоральной культуры, причем не только отдельной личности, но и общества в целом. Очевидным является то, что коммуникация зависит от уровня культуры лиц, участвующих в общении. Коммуникация в среде правонарушителей существенно отличается от коммуникации граждан, уважающих правовые предписания. Не следует также забывать, что практически отсутствует смысл в голосовании граждан, если большинство из них невежественны, некомпетентны, имеют низкий уровень политической культуры.

\section{Выводы}

Проведенное исследование позволяет утверждать о двуединстве электорально-правовой культуры и политико-правовой коммуникации на выборах Прусского ландтага (1849-1918 гг.). Культура может рассматриваться как форма коммуникации людей, электорально-правововая культура - как форма политико-правовой коммуникации. При осуще- ствлении политической коммуникации необходимо учитывать коммуникативную природу культуры. От уровня культуры зависят коммуникативные процессы. Низкая явка на выборах в ландтаг Пруссии не являлась безусловным следствием низкого уровня электорально-правовой культуры населения Пруссии, a, наоборот, может свидетельствовать о ее высоком уровне. В обществе должны быть созданы такие институты, которые являются наилучшими из возможных для данного общества. Их создание будет способствовать развитию гражданственности человека, вовлеченности его в общественные дела. Неприятие существующего положения приводит к неконструктивной, нелегальной политической активности и снижению уровня участия населения на выборах.

\section{ПРИМЕЧАНИЕ}

${ }^{1}$ Исследование выполнено при финансовой поддержке РФФИ в рамках научного проекта № 20-011-00436.

The reported study was funded by RFBR, project no. 20-011-00436.

\section{СПИСОК ЛИТЕРАТУРЫ}

1. Боков, Ю. А. Зарождение избирательных прав пруссаков (19 ноября 1808 - 30 мая 1849 года) / Ю. А. Боков // Вестник Волгоградского государственного университета. Серия 5, Юриспруденция. -2012 . - № 2 (17). - С. 99-105.

2. РГАСПИ.-Ф. 215.- Оп. 1.- Д. 11 : Листовки, газетные вырезки (1909-1917 гг.). - Л. 199 : Объявление-листовка «О проведении собрания, посвященного избирательной реформе в Пруссии».

3. РГАСПИ.-Ф. 215.-Оп. 1.-Д. 171 : Газеты и вырезки из газет за 1901-1910 гг. и 1919 г. со статьями о предвыборных кампаниях; о роспуске рейхстага (1906 г.). Журналы, листовки (1901-1910, 1919 гг.) [Б. н.] : Объявление-листовка «Избирателям ландтага 8 июня 1908 года».

4. Bundesarchiv Deutschland. - Bestand Plak 002 - Weimarer Republik. - Signatur Plak 002-020-116.

5. Gash, N. Politics in the Age of Peel: A Study in the Technique of Parliamentary Representation, 1830-1850 / N. Gash. - N. Y., 1971. - P. 105-109.

6. Königliche privilegierte Berlinische Zeitung von Staats - und gelehrten Saachen. - 07.03.1910. № 111. - S. 1. 
7. Milbrath, L.W. Political Participation. How and Why Do People Get Involved in Politics? / L. W. Milbrath. Chicago: Rand McNally \& Company, 1965. - P. 16-17.

8. Neueste Mittheilungen. - 23.10.1888. № 97. - S. 1 .

9. Provinzial-Correspondenz. - 10.02.1869. № 6. - S. 3 .

10. Verordnung über die Ausführung der Wahl der Abgeordneten zur Zweiten Kammer vom 30. Mai 1849 // Gesetz-Sammlung für die Königlichen Preußischen Staaten. - 1850. - S. 205.

11. Vorwärts. -07.03 .1910 . - № 55a. - S. 1.

\section{REFERENCES}

1. Bokov Yu.A. Zarozhdenie izbiratel'nyh prav prussakov (19 noyabrya 1808 - 30 maya 1849 goda) [The Birth of Prussian Suffrage (November 19, 1808-May30, 1849)]. Vestnik Volgogradskogo gosudarstvennogo universiteta. Seriya 5. Yurisprudenciya [Science Journal of Volgograd State University. Series 5. Jurisprudence], 2012, no. 2(17), pp. 99-105.

2. RGASPI, F. 215, Op. 1, D. 11: Listovki, gazetnye vyrezki (1909-1917 gg.). L. 199: Obyavleniye-listovka «O provedenii sobraniya. posvyashchennogo izbiratelnoy reforme v Prussii» [Leaflets, newspaper clippings (1909-1917). L. 199: Announcement-leaflet "On holding a meeting dedicated to electoral reform in Prussia"].
3. RGASPI, F. 215, Op. 1, D. 171: Gazety i vyrezki iz gazet za 1901-1910 gg. i 1919 g. so stat'yami o predvybornyh kampaniyah; o rospuske rejhstaga (1906 g.). Zhurnaly, listovki (1901-1910, 1919 gg.) [B. numeracii]: Ob"yavlenie-listovka «Izbiratelyam landtaga 8 iyunya 1908 goda» [Newspapers and Newspaper Clippings for 1901-1910 and 1919 with Articles on Election Campaigns; on the Dissolution of the Reichstag (1906). Magazines, Leaflets (19011910, 1919) [B. Numbering]: Announcement-Leaflet "To the Voters of the Landtag on June 8, 1908].

4. Bundesarchiv Deutschland. Bestand Plak 002. Weimarer Republik. Signatur Plak 002-020-116.

5. Gash N. Politics in the Age of Peel: A Study in the Technique of Parliamentary Representation, 1830-1850. New York, 1971, pp. 105-109.

6. Königliche privilegierte Berlinische Zeitung von Staats - und gelehrten Saachen, 07.03.1910, no. 111 , p. 1 .

7. Milbrath L.W. Political Participation. How and Why Do People Get Involved in Politics? Chicago, Rand McNally \& Company, 1965, p. 16-17.

8. Neueste Mittheilungen, 23.10.1888, no.97, p. 1.

9. Provinzial-Correspondenz, 10.02.1869, no. 6, p. 3 .

10. Verordnung über die Ausführung der Wahl der Abgeordneten zur Zweiten Kammer vom 30. Mai 1849. Gesetz-Sammlung für die Königlichen Preußischen Staaten, 1850, p. 205.

11. Vorwärts, 07.03.1910, no. 55a, pp. 1 .

\section{Information About the Authors}

Yuri A. Bokov, Candidate of Sciences (Jurisprudence), Associate Professor, Department of Constitutional and Municipal Law, Volgograd State University, Prosp. Universitetsky, 100, 400062 Volgograd, Russian Federation, bokov2004@yandex.ru, bokov@volsu.ru, https://orcid.org/0000-0001-6357-9599

Erwin A. Akhverdiev, Consultant, Bankruptcy Support Department, Central Office of the Federal Tax Service of Russia, Neglinnaya St, 23, 127381 Moscow, Russian Federation, erwin.gelli@mail.ru, https://orcid.org/0000-0003-4264-2821

\section{Информация об авторах}

Юрий Александрович Боков, кандидат юридических наук, доцент кафедры конституционного и муниципального права, Волгоградский государственный университет, просп. Университетский, 100, 400062 г. Волгоград, Российская Федерация, bokov2004@yandex.ru, bokov@volsu.ru, https://orcid.org/0000-0001-6357-9599

Эрвин Алибекович Ахвердиев, консультант, Управление обеспечения процедур банкротства, Центральный аппарат Федеральной налоговой службы России, ул. Неглинная, 23, 127381 г. Москва, Российская Федерация, erwin.gelli@mail.ru, https://orcid.org/0000-0003-4264-282 1 